\title{
Nubes de ceniza, campos de arena. Actividad volcánica en Costa Rica y su impacto en el sector agropecuario, 1950-2017
}

\author{
Ash Clouds, Fields of Sand. Volcanic Activity in Costa Rica \\ and Its Impact on the Agriculture Sector, 1950-2017
}

\author{
Wainer Ignacio Coto-Cedeño ${ }^{1}$ \\ Universidad Nacional, Costa Rica
}

\begin{abstract}
Resumen
Este artículo explica, desde una perspectiva histórica, la actividad eruptiva de los volcanes en Costa Rica y su impacto en la agricultura y la ganadería durante el período 1950-2017. Específicamente, la investigación analiza cómo las "lluvias de ceniza" y gases expulsados por los macizos afectaron el sector ganadero y los cultivos de algodón, maíz, arroz, papa y café, entre otros. El estudio se apoya en documentación bibliográfica y fuentes primarias disponibles en la Biblioteca Nacional, Comisión Nacional de Emergencias (CNE), Archivo Nacional de Costa Rica (ANCR), Ministerio de Agricultura y Ganadería (MAG), Red Sismológica Nacional (RSN) y Observatorio Vulcanológico y Sismológico de Costa Rica (OVSICORI).
\end{abstract}

Palabras clave: Volcanes, historia ambiental, productores agropecuarios, Costa Rica

\begin{abstract}
This article explains, from a historical perspective, the eruptive activity of the volcanoes in Costa Rica and its impact on agriculture and livestock during the period 1950-2017. Specifically, the research analyzes how the "showers of ash" and gases expelled by the massifs affected the livestock sector and the crops of cotton, maize, rice, potatoes, and coffee, among others. The study is based on bibliographic documentation and primary sources available at the National Library, the National
\end{abstract}

1 Máster en Historia Aplicada por la Universidad Nacional (UNA) de Costa Rica. Investigador de la Escuela de Historia y del Observatorio de Historia Agroecológica y Ambiental (OHAA), también de esa unidad académica. Correo Electrónico: waisin09@gmail.com / wainer.coto.cedeno@una.cr 

and Its Impact on the Agriculture Sector, 1950-2017

Emergency Commission (CNE), the National Archives of Costa Rica (ANCR), the Ministry of Agriculture and Livestock (MAG), the National Seismological Network (RSN), and the Costa Rican Volcanological and Seismological Observatory (OVSICORI).

Keywords: Volcanoes, Environmental History, Agricultural Producers, Costa Rica

"Erguido en la mitad de la maleza, eres la boca que a los cielos reza y eres la fance que a los cielos ruge. Tu apostura es la más noble apostura. Tu cólera febril todo lo aterra. Tú viste el florecer de los maizales, del árbol que nos da frutos opimos, y a la luz de reflejos matinales, la hermosa procesión de los racimos. El campo se estremece apenas lanzas tus rugidos broncos. Un pánico mortal se extiende y crece, y en la selva que el céfiro adormece los pájaros santiguan a los troncos”.

Carlomagno Araya, "El Volcán Poás” (Poema costarricense).

\section{Introducción ${ }^{2}$}

De manera un tanto injusta, los volcanes han quedado al margen de los estudios sobre Historia Ambiental en Costa Rica. Esto a pesar de que en el territorio nacional se han logrado identificar alrededor de 120 focos volcánicos (la mayoría muy antiguos y extintos) (Barquero, 2005). De este gran total, cinco han sido los principales volcanes activos, a saber: el volcán Rincón de la Vieja, volcán Arenal, volcán Poás, volcán Irazú y volcán Turrialba. Estos macizos se han convertido en una de las mayores amenazas agroecológicas para los productores de distintas regiones agrícolas y ganaderas del Valle Central, la Zona Norte y el Pacífico Norte del país (Mapa No. 1). ${ }^{3}$ La caída de ceniza en las áreas de cultivo y pastoreo ha provocado cuantiosas pérdidas económicas, el desplazamiento de productores a zonas menos afectadas por la expulsión de materiales, así como un aumento en el número de plagas. Del mismo modo, los volcanes han puesto a prueba la capacidad de respuesta tanto de las autoridades estatales como de los agricultores y ganaderos para contrarrestar los efectos de las erupciones.

2 Una versión de este artículo se presentó en la Mesa "La vulnerabilidad del paisaje" en el VIII Simposio de la Sociedad Latinoamericana y Caribeña de Historia Ambiental (SOLCHA), llevado a cabo en la ciudad de Puebla, México, por la Benemérita Universidad Autónoma de Puebla, entre el 03 y 05 de agosto del 2016.

3 Aparte de los volcanes activos al interior del territorio, el sur del país se encuentra bajo la influencia del volcán Barú. Dicho volcán se ubica al oeste de Panamá, en la provincia de Chiriquí, a $35 \mathrm{~km}$ de la frontera con Costa Rica. Ante una eventual erupción y por la dirección de los vientos (este-oeste) es probable la caída de ceniza y otros materiales en los poblados costarricenses de Ciudad Neilly, Golfito y Puerto Jiménez. Para más detalles, véase: Sherrod, 2008. 
Wainer Ignacio Coto-Cedeño. Nubes de ceniza, campos de arena. Actividad volcánica en Costa Rica y su impacto en el sector agropecuario, 1950-2017

Este artículo busca explicar, desde una perspectiva histórica, la actividad eruptiva de los volcanes en Costa Rica y su impacto en la agricultura y la ganadería durante el siglo XX. Concretamente, su objetivo es analizar cómo las "lluvias de ceniza" y gases expulsados por los macizos afectaron el sector ganadero y el cultivo de algodón, maíz, arroz, papa y café, entre otros. Para abordar la temática, el documento se dividió en tres grandes apartados. El primero consiste en una introducción teórica del objeto de estudio, la cual pretende vincular la Historia Ambiental y el concepto de resiliencia ecológica con el fenómeno de las erupciones volcánicas. El segundo apartado analiza el impacto de las erupciones en el sector agropecuario costarricense. Por último, el tercer apartado indaga sobre la participación del Estado en el diseño y ejecución de planes de emergencia para la atención de los productores.

Mapa No. 1

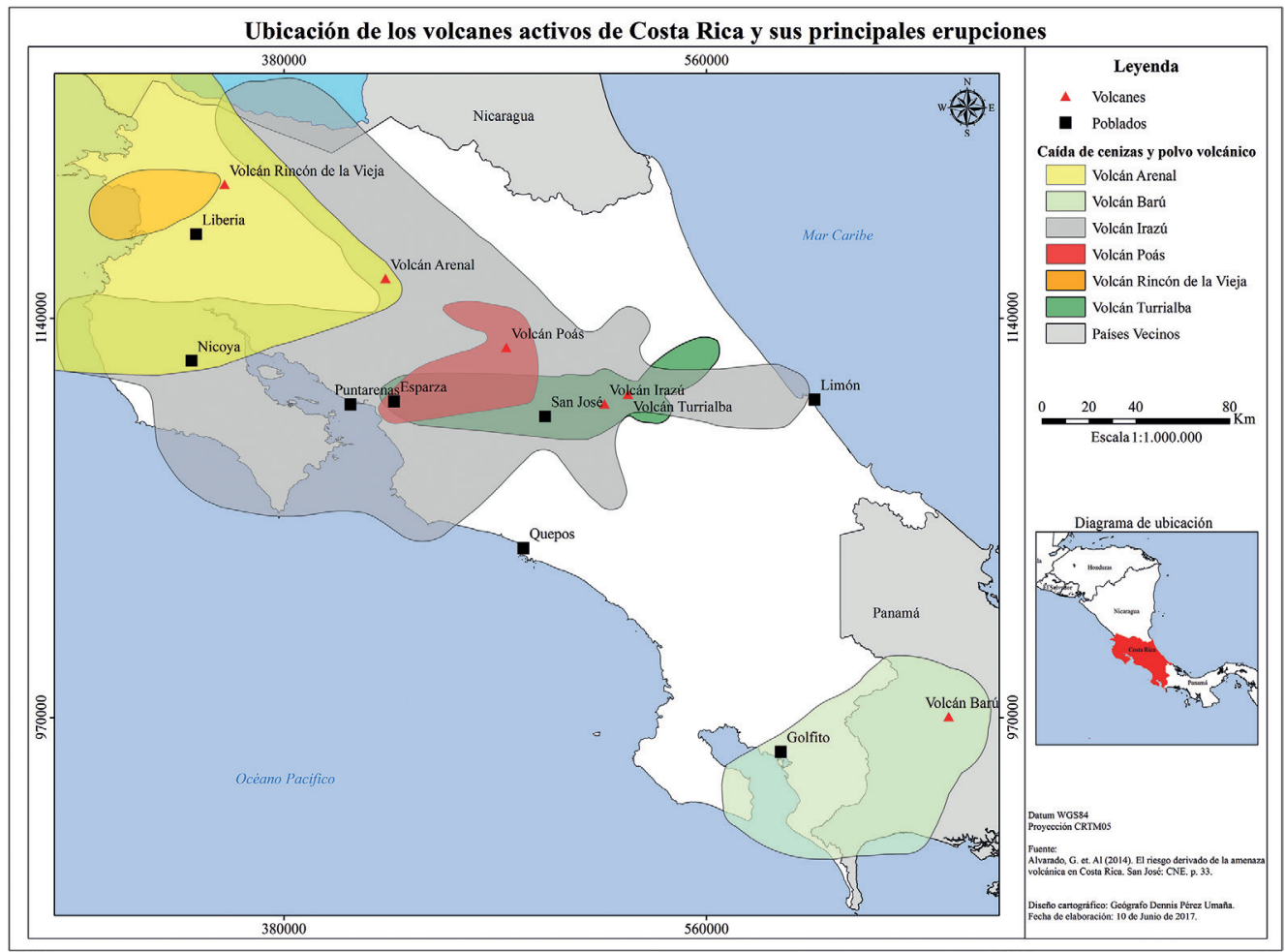

Fuente: (Alvarado, et. Al, 2014). 


\section{Historia Ambiental, volcanes y resiliencia ecológica}

Numerosos son los estudios alrededor del mundo que analizan el impacto de las erupciones volcánicas en el sector agropecuario. Destacan, al respecto, investigaciones realizadas en Italia, Indonesia, México, Hawaii, España, Argentina y Filipinas. En su mayoría, son trabajos "técnicos" elaborados por geólogos, agrónomos, biólogos, geógrafos y ecólogos. En este sentido, dichas investigaciones tienen como objetivo principal cuantificar la afectación total de las erupciones en la agricultura y la ganadería. Es decir, se ocupan de contabilizar pérdidas económicas y disminuciones en los volúmenes de producción, así como de medir las cantidades de cenizas (y otros materiales de origen volcánico) en el suelo. Ejemplos de este tipo de estudios son los publicados por Besoaín (1992a, 1995b) sobre las erupciones de los volcanes Lonquimay y Hudson en Chile durante los años 1988-1991. Del mismo modo, resalta el artículo de Cook (1981) sobre la gran erupción del Mount St. Helens en 1980 en los Estados Unidos.

Ahora bien, existe otro importante grupo de estudios internacionales que se han encargado de explicar el efecto de la ceniza volcánica en poblaciones de insectos (Elizalde, 2014). Sobresalen las pesquisas de Buteler (2011), Masciocchi (2013), Martínez (2013) y Pirk (2014), quienes analizaron las "propiedades insecticidas" de la ceniza expulsada por el complejo volcánico Puyehue-Cordón Caulle durante las erupciones del 2011. Las pruebas las efectuaron, tanto en campo como en laboratorios, y de los resultados se desprendieron tres grandes conclusiones. En primer lugar, se determinó que la ceniza posee micropartículas tóxicas que destruyen la cutícula de los insectos, provocándoles la muerte por deshidratación. En segundo lugar, lograron comprobar que la susceptibilidad a dichas partículas varió según el tipo de insecto. Para este caso en particular, las hormigas mostraron una mayor resistencia que las abejas. Por último, la alta mortalidad de las abejas y la concentración de ceniza en las flores alteraron el proceso polinizador de las plantas.

Igual de abundante es la producción bibliográfica sobre la actividad de los volcanes en Costa Rica. Fundamentalmente, se tratan de estudios académicos, monografías e informes de instituciones estatales que se especializan en la historia geológica de las formaciones volcánicas y la actividad de los macizos. Por ejemplo, destacan los documentos escritos por Bergoeing (2011), Alvarado (2013), Mora (2004) y Feldman (1993). No 
Wainer Ignacio Coto-Cedeño. Nubes de ceniza, campos de arena. Actividad volcánica en Costa Rica y su impacto en el sector agropecuario, 1950-2017

obstante lo anterior, son escasas las investigaciones que, de manera total o parcial, han estudiado el impacto de las erupciones volcánicas en el sector agropecuario del país. Desde esta perspectiva de análisis, debe tomarse en cuenta el trabajo de Aguilar y Alvarado (2014), quienes realizaron un balance de las pérdidas económicas que ocasionaron los principales volcanes activos en la agricultura y la ganadería, a lo largo del período 1953-2005. Asimismo, Ruíz y Jiménez publicaron un artículo sobre los efectos de la ceniza en el desarrollo de las plantas de café, esto a raíz de las erupciones del volcán Irazú entre 1963-1965 (Ruíz y Jiménez, 1968).

En vista de los vacíos temáticos y la falta de investigaciones con enfoques de larga duración, este artículo pretende contribuir con el estudio de los volcanes en Costa Rica desde una postura teórica que combine las propuestas de la Historia Ambiental y la resiliencia ecológica. La Historia Ambiental, desde su interpretación más clásica, se encarga de explicar las relaciones entre sociedad y naturaleza. En palabras de González de Molina, es el "estudio histórico de la evolución y del cambio de las sociedades humanas, en el que los procesos naturales y sociales son considerados como agentes activos en permanente y mutua determinación" (González de Molina, 2003, pp. 28-29; Watson, 2003). De igual manera, la Historia Ambiental analiza el azar y la imprevisibilidad en la interacción entre sociedad y naturaleza. Es decir, indaga en aquellos fenómenos que "sin una causación lógica" alteran el orden y la dinámica del medio físicobiológico. Usualmente, se catalogan comofenómenos azarosos los sismos, tsunamis y las erupciones volcánicas (Meritano, 2011). ${ }^{4}$

La resiliencia ecológica, por su lado, busca comprender los procesos a través de los cuales los sistemas socioecológicos se automantienen y persisten frente a las perturbaciones y los cambios (Holling, 2001b; Müller, Burkhard y Kroll, 2010). Para ello parte de dos indicadores primordiales: la capacidad de adaptación y la estabilidad. La primera, propone la idea de un medio ambiente inestable, variable en el tiempo y en el espacio,

4 Sobre la relación entre azar e Historia Ambiental, Manuel González de Molina señala lo siguiente: "los historiadores ambientales deben prestar atención al azar, factor éste ignorado completamente por la historiografía tradicional. Puede interpretarse en un sentido lato: un fenómeno que ocurre por azar como producto de la interacción de una multiplicidad de fenómenos encadenados y que no puede ser previsto. Pero puede interpretarse también como el resultado lógico (aunque también imprevisible a nuestro nivel actual de conocimientos) de las interacciones entre dinámicas sociales, geográficas, de poder y cambios ambientales. Es lo que [C.S.] Holling llama una 'sorpresa' en la propia dinámica interactiva entre la sociedad y la naturaleza” (González de Molina, 2003, pp. 35-36). 
pero que a la vez tiene el potencial para generar respuestas adaptativas ante eventos inesperados e impredecibles. La segunda, sugiere la posibilidad de que los ecosistemas se extingan. A este respecto, C. S. Holling (1973a) plantea que cuánto más homogéneos y estables son los sistemas socioecológicos menor capacidad de adaptación poseen y, por ende, tienen mayores probabilidades de extinguirse. En términos generales, el concepto de resiliencia ecológica hace hincapié en la adaptación como estrategia de evolución y en la estabilidad como forma de extinción.

En países como Nueva Zelanda, Italia e Islandia diferentes investigaciones han recurrido al concepto de resiliencia ecológica para explicar el desarrollo de comunidades humanas que se encuentran bajo la influencia de volcanes activos. Es importante resaltar el valor que dichas investigaciones le atribuyen al conocimiento histórico. Esto porque lo conciben como un instrumento metodológico que permite "medir" (en el tiempo) la capacidad de adaptación de las sociedades ante las erupciones volcánicas. Por ejemplo, Scarpati (2016), Gerrard y Petley (2013) estudiaron, a partir de fuentes arqueológicas, el proceso de recuperación de asentamientos, edificaciones y campos de cultivo que se dio después de las erupciones del volcán Vesubio a lo largo de los siglos I-XV d.C. Incluso, algunos de estos trabajos intentan formular prácticas de reducción del riesgo y de evaluación de la vulnerabilidad (Paton, 2001; Gardner y Dekens, 2007). Lo anterior, con el propósito de implementar programas de gestión ambiental que contribuyan a aumentar la resiliencia (Ágústsdóttir, 2015).

Luego de este breve repaso teórico y de revisar la literatura escrita, es válido preguntarse: ¿Es posible establecer vínculos entre la Historia Ambiental y la resiliencia ecológica? ¿Cuál es el aporte de esta "fusión” al discurso historiográfico y en general al discurso de las denominadas disciplinas híbridas? ${ }^{5}$ Si bien es cierto, que se trata de dos líneas de interpretación distintas, tanto la Historia Ambiental como la resiliencia ecológica tienen una preocupación en común: la sustentabilidad. Entendida como la evolución de los sistemas socioecológicos en el tiempo y los costes sociales, ambientales y económicos que implica la mutua determinación entre sociedad y naturaleza (González de Molina, 2011). La unión de estos

5 Se definen como disciplinas híbridas aquellas "modalidades interdisciplinarias de aproximación a la realidad basadas en la integración del estudio sintético de la naturaleza y el estudio de diferentes dimensiones de la realidad social o humana". Véase: Toledo, 2015. 
Wainer Ignacio Coto-Cedeño. Nubes de ceniza, campos de arena. Actividad volcánica en Costa Rica y su impacto en el sector agropecuario, 1950-2017

paradigmas favorece, además, la revitalización de campos tradicionales del conocimiento histórico y de áreas interdisciplinarias, tales como la Historia Agraria y la Agroecología. En este sentido, la articulación de dichos enfoques supone reconocer la inestabilidad de los sistemas agrarios, sobre todo si se incorporan en su dinámica actores ignorados, hasta el momento, como los volcanes.

\section{Plagas, lluvia ácida y ceniza. Impacto de las erupciones volcáni- cas en el sector agropecuario costarricense}

En los últimos 117 años, el país experimentó un intenso proceso de actividad volcánica. A lo largo de este período, 1900-2017, se registraron un total de 60 erupciones, es decir, aproximadamente una erupción cada dos años (Gráfico No. 1). El más activo de los volcanes fue el Poás, el cual hizo erupción en 17 ocasiones, le siguieron el Arenal con 13, el Irazú con 12, el Rincón de la Vieja con 11 y el Turrialba con 7 (Gráfico No. 2). ${ }^{6} \mathrm{La}$ etapa más aguda de la actividad se presentó después de la década de 1950. Esto porque, a partir de ese momento la potencia de las erupciones aumentó de forma considerable y los materiales volcánicos (ceniza y lluvias ácidas) causaron importantes daños en áreas de producción agropecuaria. Concretamente, las erupciones impactaron los cultivos de papa, cebolla, hortalizas, café, pastos, algodón, granos básicos, tabaco y caña de azúcar en las provincias de San José, Alajuela, Cartago, Heredia y Guanacaste, tal y como se muestra en el Mapa No. 2.

6 El conteo de erupciones corresponde a cálculos propios. Años de erupción: 1904, 1907-1908, 1910, 1914, 1915, 1953-1955, 1963, 1967, 1971, 1971, 1974, 1987-1989, 1994, 2005, 2009, 2017 (volcán Poás); 1906, 1916, 1922, 1937, 1950, 1958-1960, 1965, 1968, 1973, 1975, 1993, 1998, 2000-2001 (volcán Arenal); 1917-1918, 1919, 1920-1921, 1924, 1928, 1930, 1933, 1939-1940, 1961, 1963-1965, 1976, 1994 (volcán Irazú); 1912, 1922, 1966-1967, 1983, 1984, 1985-1987, 1991-1992, 1995, 1998, 2016 y 2017 (volcán Rincón de la Vieja); 1996, 2003, 2007, 2009, 2010, 2012, 2014-2017 (volcán Turrialba). 
Wainer Ignacio Coto-Cedeño. Ash Clouds, Fields of Sand. Volcanic Activity in Costa Rica and Its Impact on the Agriculture Sector, 1950-2017

Gráfico No. 1. Total de erupciones volcánicas en Costa Rica, 1900-2017

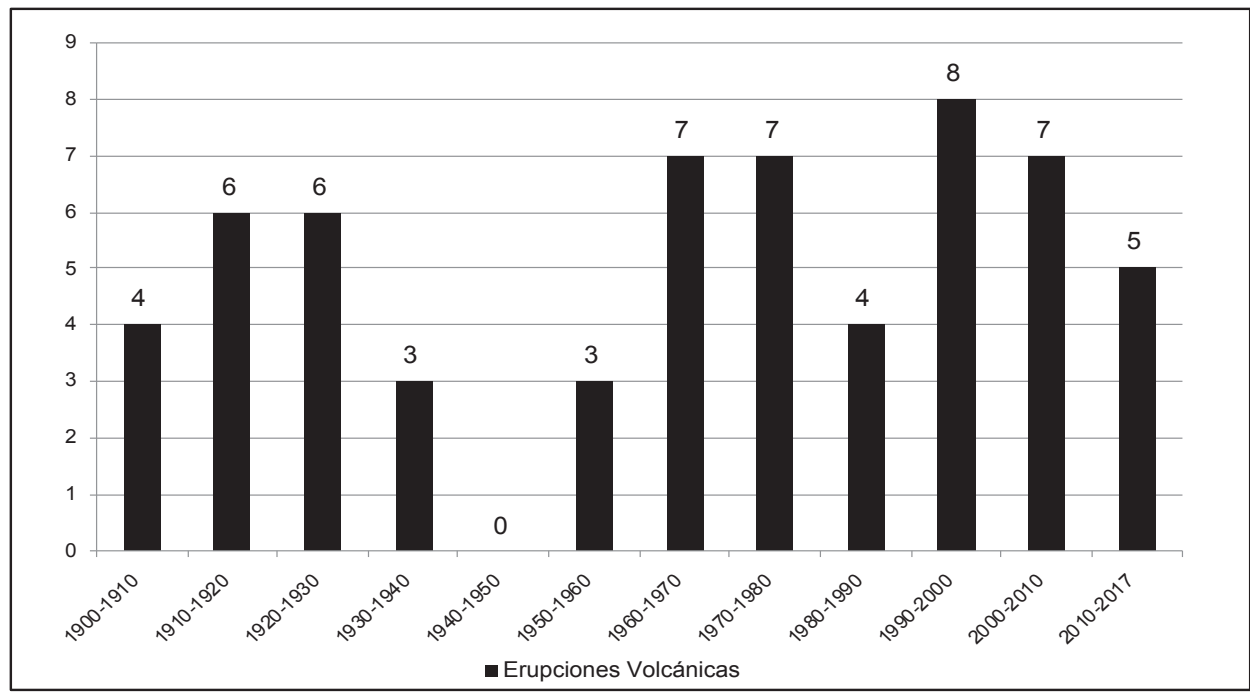

Fuente: elaboración propia con base en Mora, et. Al., 2004; Barquero, 1977; Acevedo, 1976.

Gráfico No. 2. Número de erupciones por volcán, Costa Rica, 1900-2017

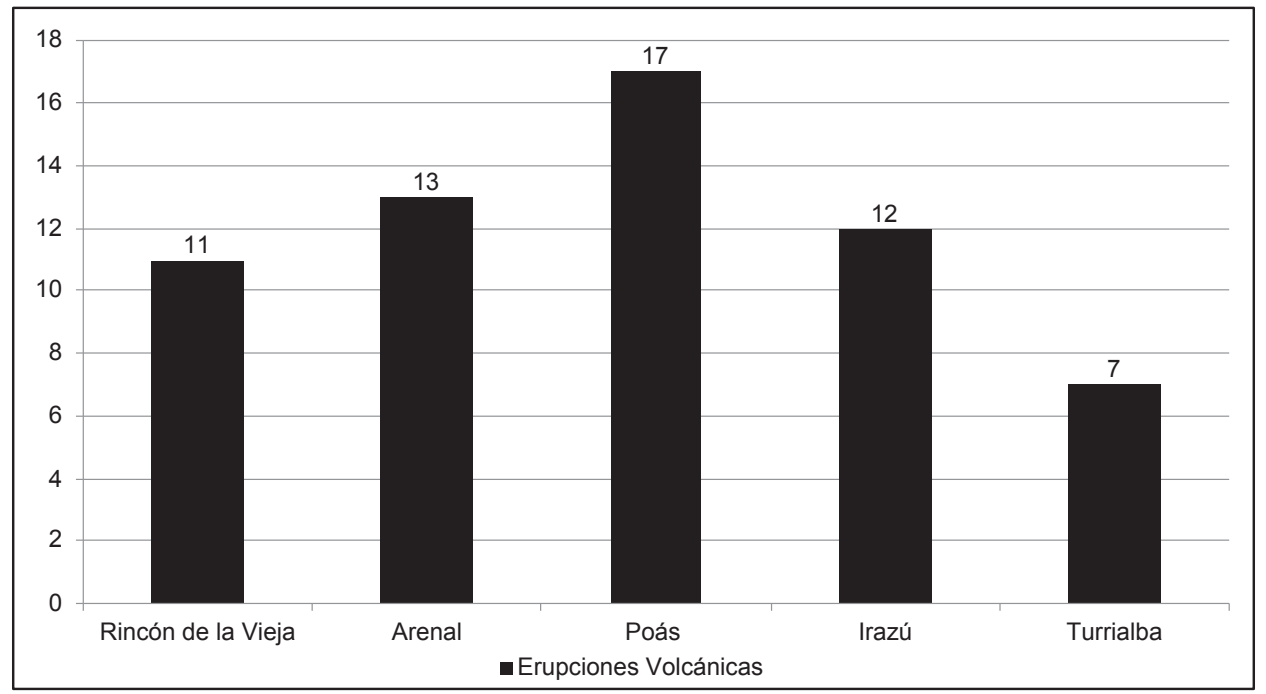

Fuente: elaboración propia con base en Mora, et. Al., 2004; Barquero, 1977; Acevedo, 1976. 
Wainer Ignacio Coto-Cedeño. Nubes de ceniza, campos de arena. Actividad volcánica en Costa Rica y su impacto en el sector agropecuario, 1950-2017

Mapa No. 2

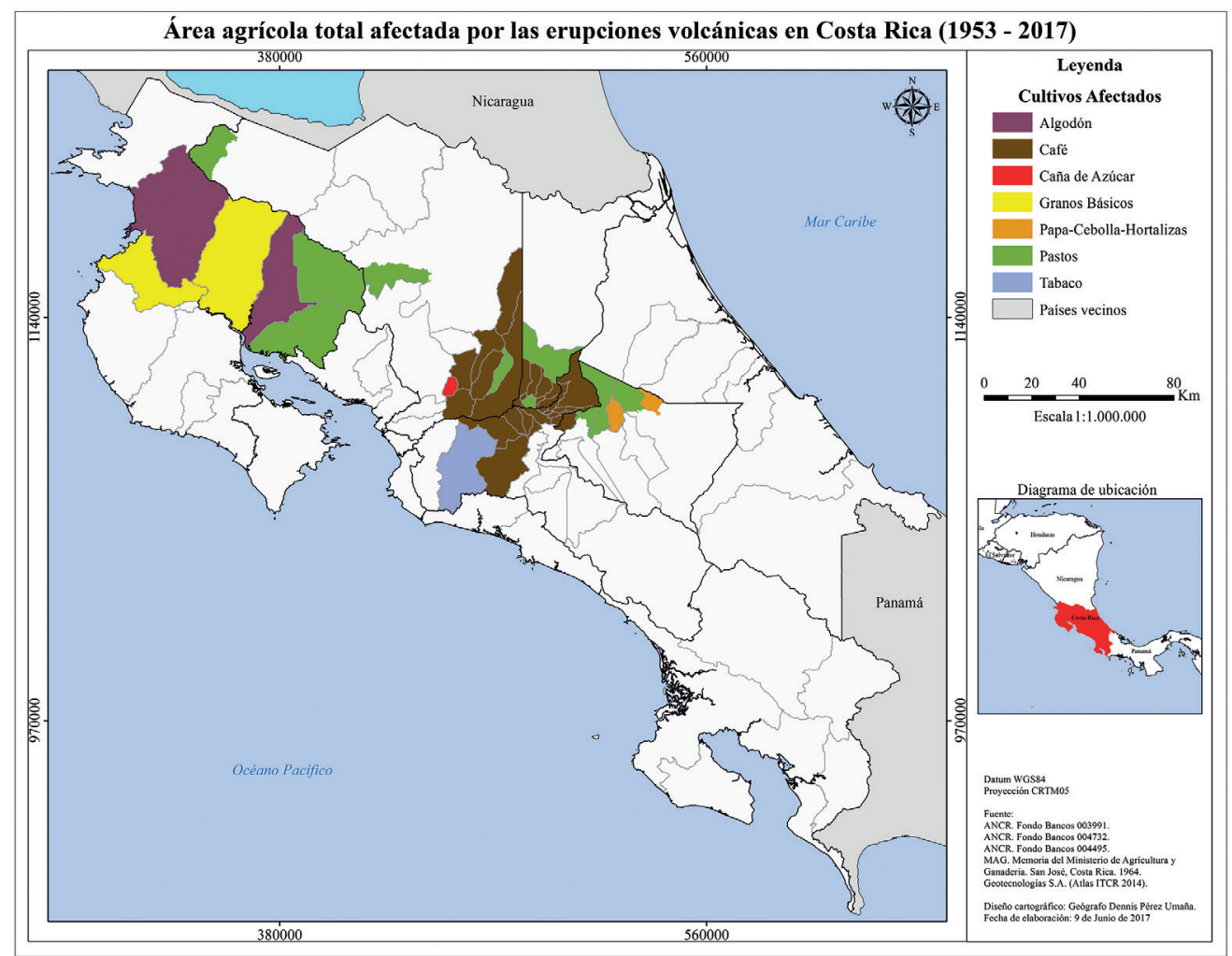

Fuente: (ANCR, 3991; ANCR, 4732; ANCR, 4495; MAG, 1964).

Del total de erupciones contabilizadas, seis fueron las que mayor afectación provocaron en el sector agropecuario costarricense, a saber: la del Irazú en 1963-1965, Arenal en 1968, Poás en 1987-1989, 1994, 2005 y Turrialba en 2014-2017.7 A pesar de las dificultades en el rastreo de las fuentes, fue posible recopilar información estadística que permitió "medir" el impacto de estas erupciones en las áreas de cultivo y pastoreo. Así, por ejemplo, para 1963-1965 el Ministerio de Agricultura y Ganadería (MAG) reportó pérdidas por caída de ceniza y lluvia ácida en 88260 hectáreas de terreno, 24780 en 1968 y 16346 entre 1994-2005, tal y como se observa en el Gráfico No. 3. Es importante mencionar, que para el caso de las

7 Otro de los impactos ambientales más significativos de las erupciones volcánicas fue la contaminación de los ríos y las fuentes de agua potable. Situación que experimentaron los pobladores de Guanacaste durante las erupciones del volcán Rincón de la Vieja en el año 1967. Para más detalles, véase: ANCR, 002576. 
erupciones del volcán Turrialba se obtuvieron datos parciales, referentes en su mayoría a cultivos hortícolas. En este sentido, se lograron determinar daños por causa de material volcánico en 221 hectáreas de papa, 62 de cebolla, 38 de repollo, 28 de coliflor, 24 de zanahoria y 16 de brócoli (Barquero, 2017).

Gráfico No. 3. Área de producción agrícola y pastoreo afectada por las erupciones volcánicas en Costa Rica, 1963-1965, 1968, 1994-2005, datos en hectáreas

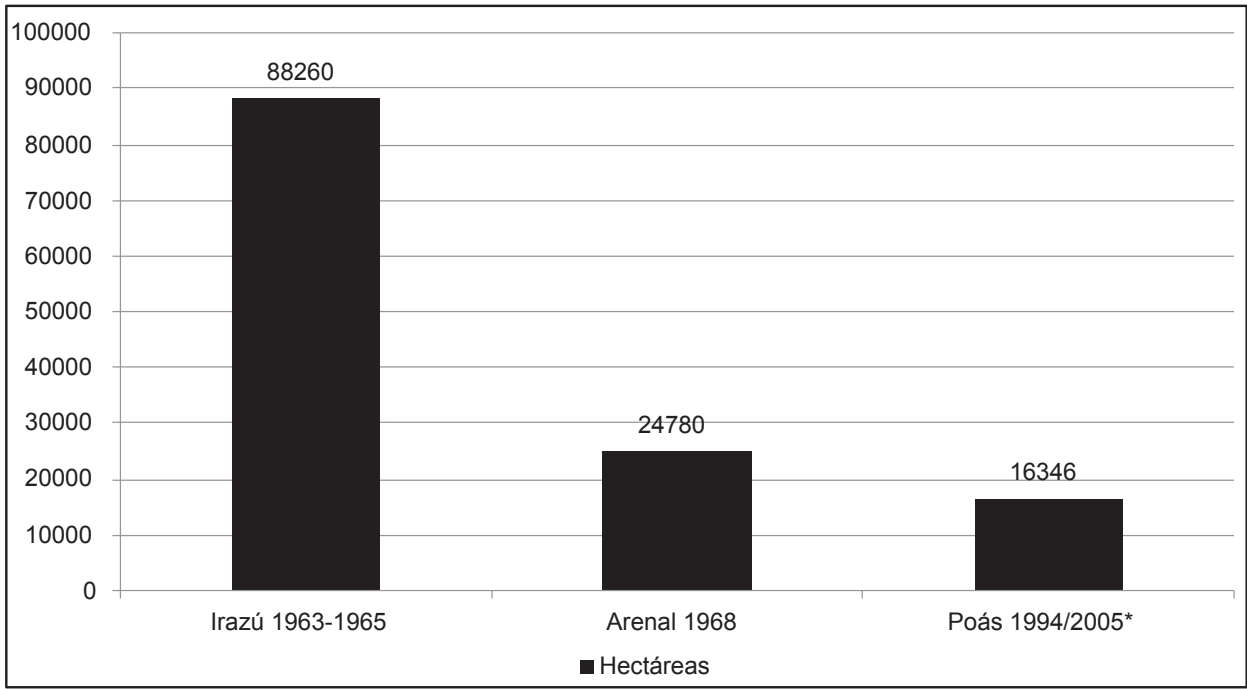

Fuente: elaboración propia con base en Aguilar y Alvarado, 2014.

Nota: *los datos para el volcán Poás corresponden a la sumatoria de las hectáreas afectadas en ambas erupciones.

Hay que recalcar, en este balance, el doble impacto de las erupciones volcánicas en el sector ganadero de leche del país (Fotografía No. 1). El primero y más evidente, fue el daño que ocasionaron en los pastizales. Basta señalar, que solo durante las erupciones del volcán Irazú, entre 19631965, el 65 por ciento del área agrícola afectada correspondió a pastos, es decir, alrededor de 57700 hectáreas. En un alto porcentaje, pastos (de piso y corte) de las variedades Kikuyo (Pennisetum clandestinum), OrchadGrass (Dactylis glomerata L.), Ray-Grass (Lolium multiflorum), Gigante (Pennisetum purpureum) e Imperial (Axonopus scoparuis). Sin embargo, 
Wainer Ignacio Coto-Cedeño. Nubes de ceniza, campos de arena. Actividad volcánica en Costa Rica y su impacto en el sector agropecuario, 1950-2017

es oportuno aclarar que, hubo variedades más susceptibles que otras al efecto de la ceniza. Así quedó demostrado en una de las visitas que realizaron funcionarios del MAG a la Zona Norte de Cartago. En su informe los expertos explicaron lo siguiente: "los pastos de piso, y muy especialmente el Kikuyo, no muestran signos de estar afectados; entre los pastos de corte, se notó el efecto de la ceniza en el Imperial y el Guate (maíz forrajero) y en menor escala en el Gigante" (ANCR, 4495).

Fotografía No. 1. Impacto de las erupciones volcánicas en el sector ganadero de leche, Costa Rica

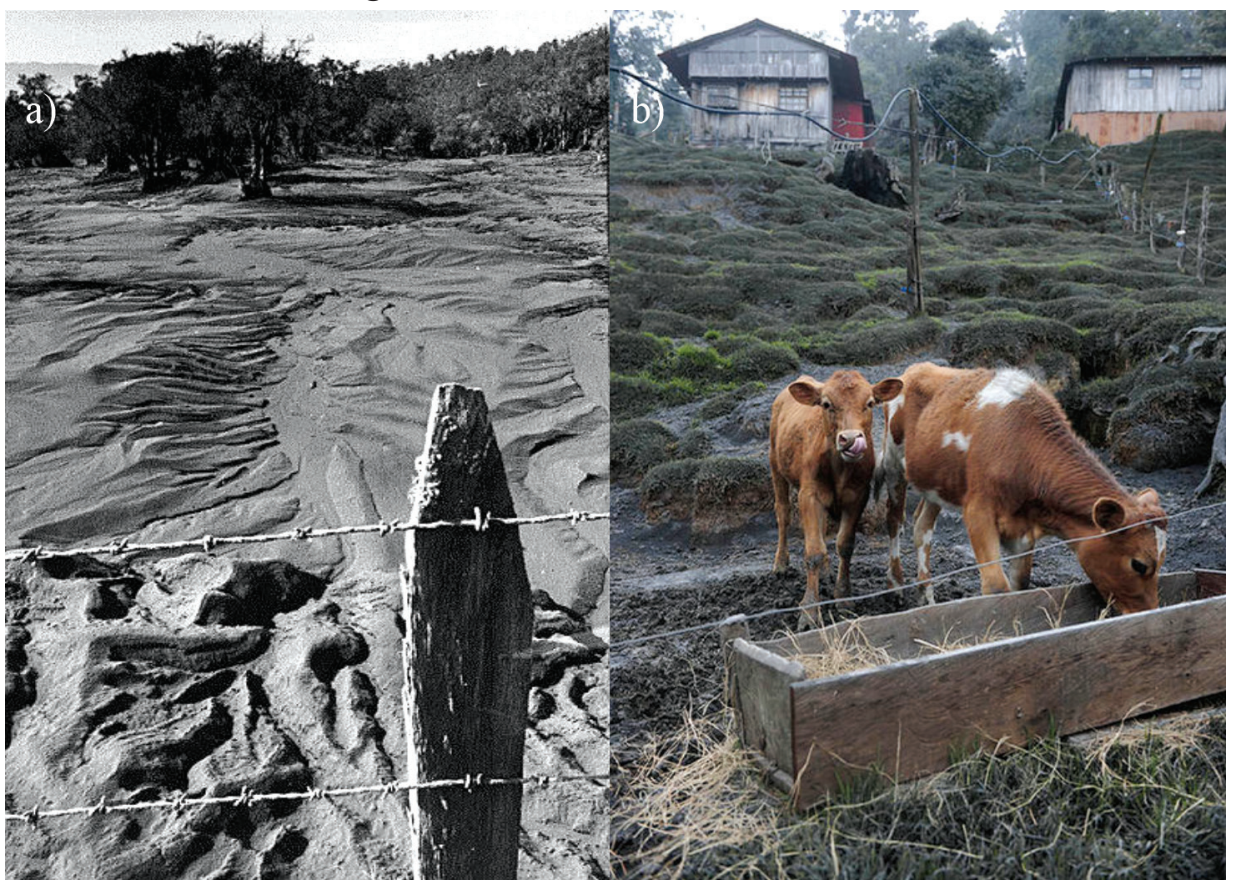

Fuente: Colección del Archivo Nacional de Costa Rica (ANCR) y Mata, 2016.

Notas: a) pastos inundados de ceniza y arena en la Zona Norte de Cartago, erupciones del volcán Irazú 1963-1965. Se reportaron pérdidas en cercas, caminos, abrevaderos y lecherías y b) ganado afectado por las erupciones del volcán Turrialba (2016), en la fotografía se observa la acumulación de ceniza en los pastos y en los cuerpos de los animales.

El segundo fue el impacto directo de las erupciones sobre los hatos de ganado vacuno. En términos generales, se contabilizaron 42000 cabezas de ganado afectadas por las erupciones del Irazú entre 1963-1965, 30 
000 por las del Arenal en 1968, 173 por las del Poás en 1994 y 4826 por las del Turrialba entre 2007-2017, tal y como se aprecia en el Gráfico No. 4. Específicamente, la principal afectación para los animales fue el consumo de pasto contaminado por la ceniza. De hecho, veterinarios y zootecnistas del MAG determinaron que la ingesta de ceniza, en grandes cantidades, provocó irritación intestinal, diarreas, úlceras, parálisis caquéxica, abortos y la muerte del ganado. Las razas enfermas fueron: Jersey, Holstein, Guernsey, Ayrshire y Pardo Suizo (ANCR, 4495). Esta situación ocasionó una disminución en la producción de leche, el desabastecimiento parcial del líquido en algunas regiones del país y, por último, se dio un incremento en el precio del producto en el mercado. ${ }^{8}$

Gráfico No. 4. Cabezas de ganado afectadas por las erupciones volcánicas en Costa Rica, 1963-2017

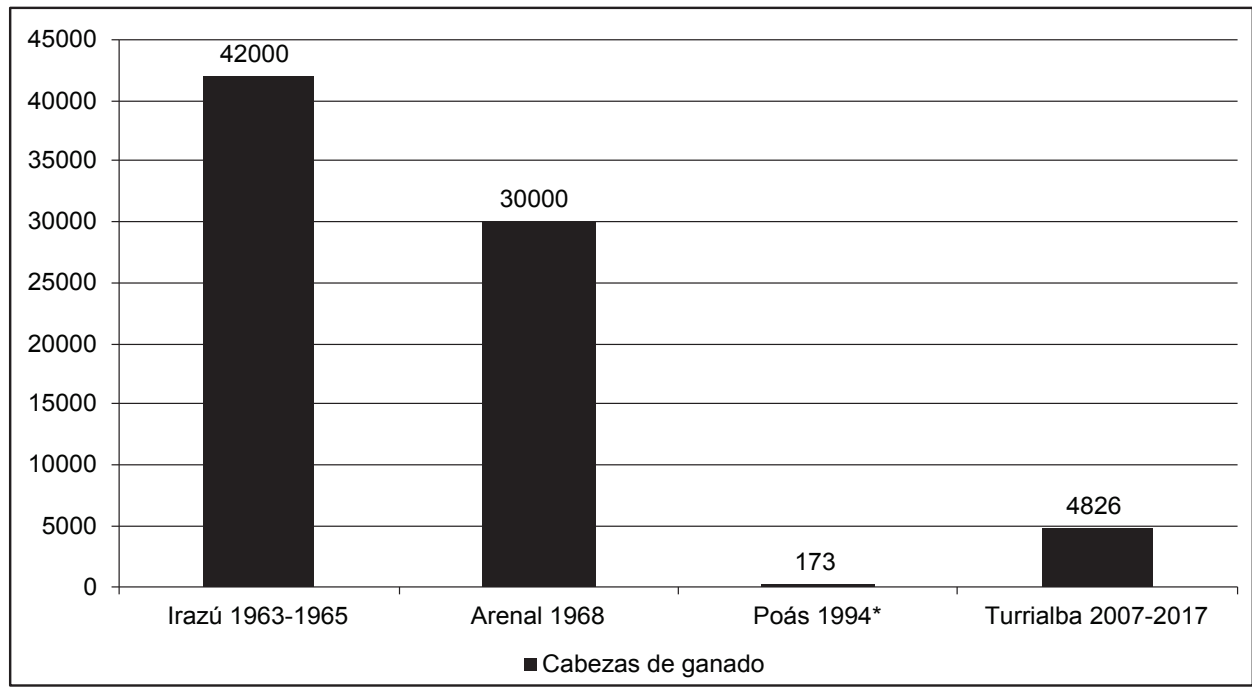

Fuente: elaboración propia con base en MAG, 1963; Fuente, 1994; Barquero, 2007 y Barquero, 2017. Nota: *datos parciales.

Ahora bien, las erupciones volcánicas originaron, además, una serie de "efectos secundarios" en los agroecosistemas. Por una parte, la acumulación de ceniza en las hojas de las plantas impidió el proceso de

8 En el caso de las erupciones del volcán Irazú, 1963-1965, se estimó una disminución del 50 por ciento en la producción de leche. Para más detalles, véase: Horton y McCaldin, 1964. 
Wainer Ignacio Coto-Cedeño. Nubes de ceniza, campos de arena. Actividad volcánica en Costa Rica y su impacto en el sector agropecuario, 1950-2017

fotosíntesis en los cultivos de café y papa. Particularmente, el efecto de la ceniza se manifestó a través de una alteración en la dinámica de fijación del carbono. Esto implicó una pérdida constante de energía y un desequilibrio en la fisiología de la planta. Asimismo, dicha alteración, causó disminuciones considerables en las cosechas y la defoliación (o muerte) de los cultivos. Aunque para el caso del café estas variaciones dependieron, en gran medida, de la variedad, edad de la planta, maduración de la hoja y altitud de la región productora (Ruíz y Jiménez, 1968). El panorama descrito fue relatado por un productor de papa, de la Zona Norte de Cartago, que resistió las erupciones del volcán Turrialba de los diez últimos años: "la ceniza tapa las hojas de las plantas, y como estas se desarrollan con la luz del día, el proceso de fotosíntesis se detiene, se marchitan, baja el crecimiento del tubérculo y hay menor rendimiento" (Solano, 2016).

Por otra parte, las "lluvias de ceniza" favorecieron el aumento de plagas en distintos cultivos agrícolas. Este incremento se dio a raíz de las erupciones de los volcanes Irazú (1963-1965) y Arenal (1968). Al respecto, cuatro fueron los cultivos afectados: caña de azúcar, pastos de la variedad Kikuyo, algodón y café (Mapa No. 3). El listado de plagas estuvo encabezado por el áfido amarillo (Sipha flava) que atacó plantaciones de caña de azúcar en los cantones de Grecia, Naranjo y Palmares. Los potreros de pasto Kikuyo situados en Coronado, Goicoechea, Llano Grande y La Unión sufrieron los embates de la baba de culebra (Prosapia distanti). El cultivo de algodón, en el cantón de Cañas, Guanacaste, experimentó el hostigue del mal del talluelo (Rhizoctonia solani), el perforador de la hoja (Bucculatrix thuberiella), áfidos (Aphis gossypii) y escarabajos (Anthonomus grandis Boh) (MAG, 1968). Finalmente, los cafetales de las provincias de Heredia y Alajuela enfrentaron los ataques de la cochinilla harinosa (Planococcus citri), el gusano minador de hojas (Leucoptera coffella), la araña roja (Oliggonychus yothersi), las escamas (Coccidae) y el pulgón (Toxoptera citricida) (Wille y Fuente, 1975). 


\section{Mapa No. 3}

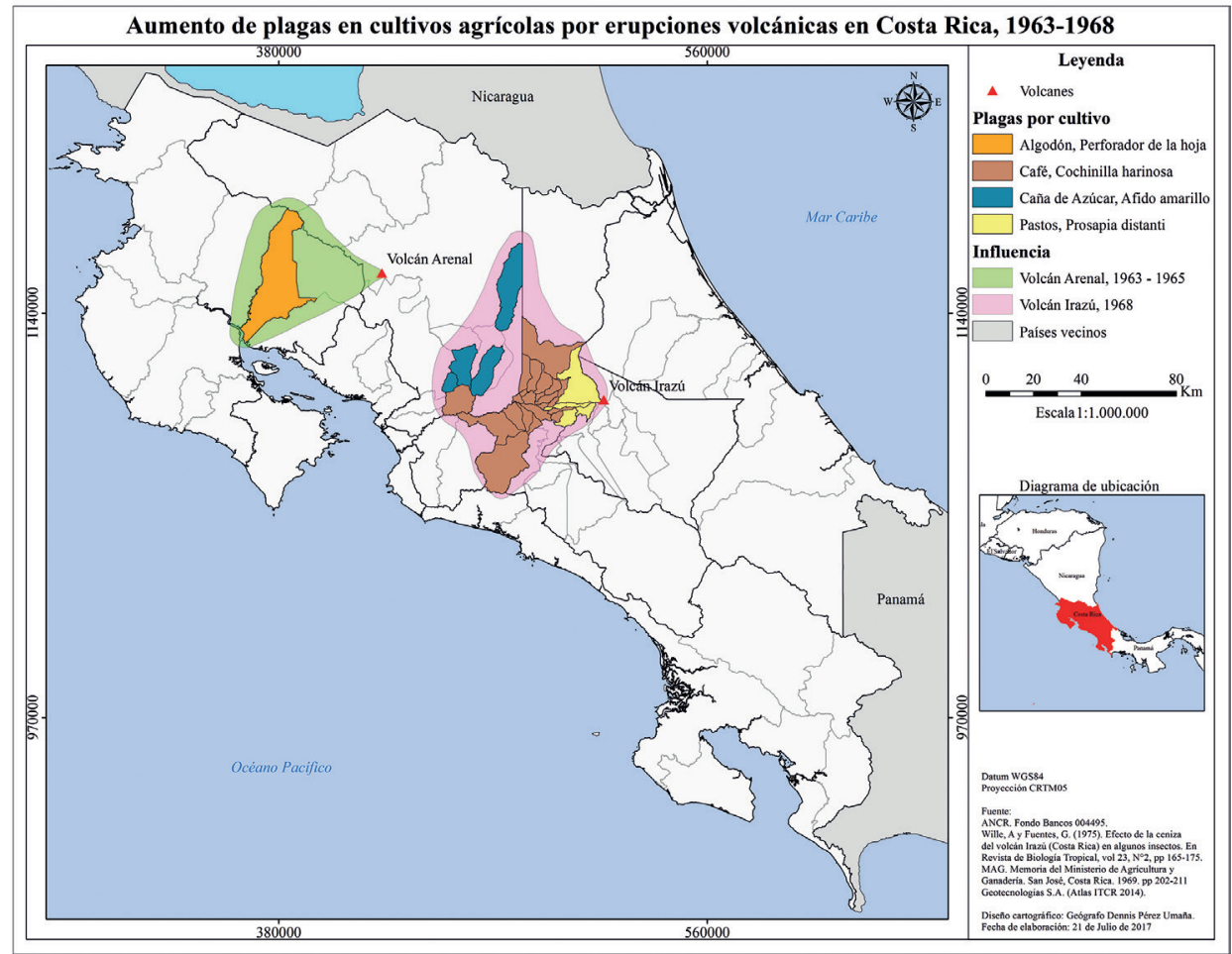

Fuente: (ANCR, 4405; Willie y Fuentes, 1975; MAG, 1969).

Si bien es cierto, que no se dispone de datos estadísticos para todos los cultivos, el café se convirtió en el principal parámetro para medir el avance de las plagas. De las 25200 hectáreas afectadas por la caída de ceniza, entre 1963-1965, el 100 por ciento registró daños por la cochinilla harinosa. Del mismo modo, el 56 y 39 por ciento, es decir, 14000 y 9800 ha respectivamente, sufrió afectación por el ataque de las escamas y el gusano minador de hojas. En menor proporción, el pulgón y la araña roja representaron un problema para el 14 por ciento del área dañada por las erupciones del Irazú, alrededor de 3500 ha, tal y como se indica en el Gráfico No. 5. ${ }^{9}$ Este

9 Funcionarios de la Sección Cafetalera del Banco Nacional de Costa Rica informaron así sobre la problemática del café: "[hemos] comprobado serios ataques del "minador", pequeña mariposa que se nutre del parénquima de las hojas causando su muerte; también se ha observado el desarrollo del ácaro, pequeña araña roja que, junto con algunos áfidos, destruyen tanto hojas como crecimientos tiernos y retoños, impidiendo la formación de nueva cosecha". Véase: ANCR, 4495. 
Wainer Ignacio Coto-Cedeño. Nubes de ceniza, campos de arena. Actividad volcánica en Costa Rica y su impacto en el sector agropecuario, 1950-2017

desequilibrio biológico se debió al "efecto insecticida" de la ceniza volcánica, el cual provocó la destrucción de los enemigos naturales de ácaros e insectos comunes en las plantaciones de café..$^{10}$ De igual manera, la sequía (y el viento) que azotó al país en esos años contribuyó enormemente en el crecimiento de las distintas plagas del cafeto.

Gráfico No. 5. Porcentaje de hectáreas de café afectadas por plagas durante las erupciones del volcán Irazú, 1963-1965

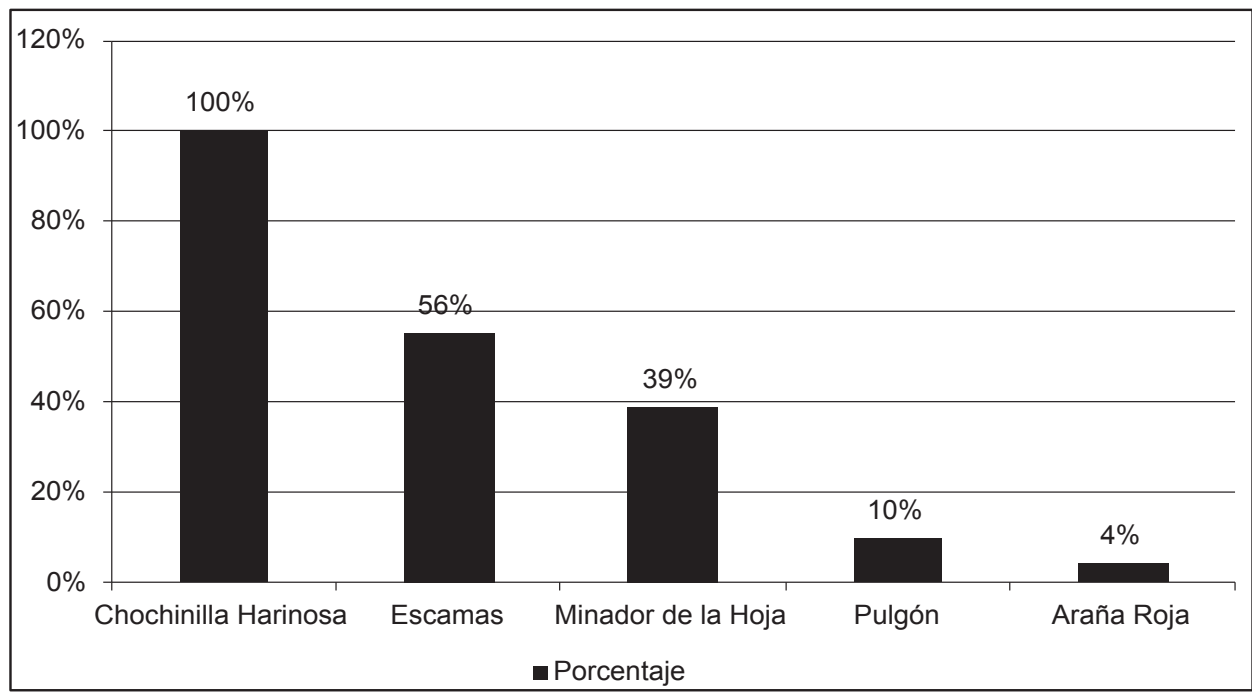

Fuente: elaboración propia con base en MAG, 1964.

Con el objetivo de reestablecer el orden ecológico, el MAG desarrolló estrategias para combatir las plagas. La primera, consistió en la introducción de insectos depredadores en las fincas cafetaleras. Así, por ejemplo, en 1964 se introdujeron en los cafetales del Valle Central, especies como la vaquita (Cryptolaemus montrouzieri) y el abejón (Stethorus sp.), las cuales actuaron como agentes de control biológico en las poblaciones de la cochinilla harinosa (Hilje y Saunders, 2008). La segunda de las estrategias tuvo como finalidad acabar con las plagas por medio del uso intensivo de agroquímicos. En los trabajos de fumigación, aéreos y terrestres, se emplearon insecticidas como el Malathión, Diazinón, Phorato y Lannate; este último

10 El "efecto insecticida" de la ceniza también ocasionó la muerte de abejas en la provincia de San José. La muerte de estos insectos se dio por la ingesta y exposición de los nidos y flores a la ceniza. 
se utilizó mayoritariamente en el cultivo de algodón (MAG, 1969; ANCR, 8875). Es importante apuntar, que la aplicación de la dosis varió según el comportamiento y la resistencia de las plagas al insecticida, así como a las condiciones climáticas (MAG, 1964; Sin Autor, 1968; Sin Autor, 1964). La implementación de este tipo de prácticas significó elevar los costos de operación, ya que, como se analizará en el siguiente apartado, en algunos casos los productores no recibieron apoyo estatal.

\section{Planes de emergencia y estrategias de adaptación ante las erupciones}

Indudablemente, las erupciones obligaron a las autoridades de gobierno a ejecutar programas de asistencia agropecuaria en beneficio de agricultores y ganaderos. Los programas contaron con el financiamiento de organismos internacionales como el Banco Interamericano de Desarrollo (BID), la Agencia de los Estados Unidos para el Desarrollo Internacional (USAID) y la Organización de las Naciones Unidas para la Agricultura y la Alimentación (FAO) (Sin Autor, 1968). ${ }^{11}$ Asimismo, se recibieron diferentes donativos de países como Japón y Venezuela. La ayuda económica fue administrada por el Sistema Bancario Nacional (SBN), el Ministerio de Agricultura y Ganadería (MAG) y el Consejo Nacional de Producción (CNP). Aparte de las entidades mencionadas, los programas recibieron ayuda complementaria del Instituto de Fomento Cooperativo (INFOCOOP), la Dirección Nacional de Desarrollo de la Comunidad (DINADECO) y la Cooperativa de Productores de Leche Dos Pinos R. L. (Sin Autor, 1990).

Los subsidios se distribuyeron de la siguiente manera. Los productores agrícolas recibieron donaciones de insumos (fertilizantes, semillas y agroquímicos), mantenimiento técnico de cultivos, facilidades para el otorgamiento de créditos, indemnizaciones y la condenación de deudas (ANCR, 4732). Por su parte, el sector ganadero de leche obtuvo asistencia médico-veterinaria y alimentos para los animales. Concretamente, el MAG, en conjunto con otras instituciones, llevó a cabo campañas de vacunación y suministró medicamentos al ganado enfermo. Además, distribuyó pastos de corte, mezclas de concentrado, melaza y "alimento verde" (MAG, 1963; Sin Autor, 1963). De forma paralela, entregó equipos como sopladoras y bombas de motor para eliminar el exceso de ceniza en los

11 Para 1968 se contó con la colaboración del Programa Mundial de Alimentos (PMA) de la Organización de las Naciones Unidas (ONU). Obsérvese: ANCR, 0733. 
Wainer Ignacio Coto-Cedeño. Nubes de ceniza, campos de arena. Actividad volcánica en Costa Rica y su impacto en el sector agropecuario, 1950-2017

potreros (MAG, 2016). Debido a la magnitud de las erupciones, sobre todo las de 1963-1965 y 1968, el Ministerio diseñó un plan especial de sacrificio y exportación de ganado. El plan buscó seleccionar las vacas jóvenes y sanas para venderlas en Centroamérica y Panamá. Por el contrario, los animales que, por edad, mala condición de la ubre y problemas de esterilidad fueron sacrificados (ANCR, 4495; Sin Autor, 1968).

Otro de los programas que se impulsó fue la adjudicación de tierras del Estado a los productores que más afectación experimentaron por las erupciones. La entrega de las propiedades se gestionó a través del SBN, MAG, CNP y el Instituto de Tierras y Colonización (ITCO). El primer "Programa de colonización para damnificados por la actividad volcánica" se formuló después de las erupciones del volcán Poás entre 19531955. En esa ocasión, se trasladaron 30 familias campesinas del cantón de Grecia a la colonia San Vito de Java en la provincia de Puntarenas. ${ }^{12}$ El segundo, se estableció entre 1963-1965 y otorgó tierras a 1000 familias de todo el país que resultaron perjudicadas por las erupciones del Irazú. Para ese momento, se reubicó a las personas en Guayabo de Turrialba, Astúa Piere de Limón y Coto Brus de Puntarenas (ITCO, 1964). En 1970, luego de las erupciones del volcán Arenal de 1968, se creó un tercer proyecto; el cual tuvo como finalidad trasladar 100 ganaderos del cantón de Tilarán a las colonias de Bajos Los Cartagos y Río Frío en Alajuela (ANCR, 1453).

No obstante, lo anterior, la labor del MAG fue duramente criticada por los productores. Las fricciones entre el sector agropecuario y las autoridades del MAG surgieron a partir de las erupciones del Irazú (1963-1965) y del Poás en 1994. En este sentido, tanto ganaderos como agricultores reprocharon la pasividad e indiferencia con la que el Ministerio atendió las solicitudes de ayuda. Los reclamos se hicieron por incumplimientos en la distribución de los insumos, la negativa de los bancos para condenar las deudas y la falta de colaboración en el proceso de evacuación del ganado. Expresiones como "del MAG no hemos recibido ninguna ayuda, esta situación es la ruina de Cartago, que vive de la leche y las papas" (Sin Autor, 1963), "el Ministerio de Agricultura lo único que hizo fue ofrecer semillas, sin embargo, la entrega nunca se dio" (Víquez, 2015) y "los lamentos de los agricultores de las zonas

12 Debido a que el ITCO se fundó hasta el año de 1961, el primer proyecto de colonización estuvo a cargo de la Sección de Juntas Rurales de Crédito Agrícola (SJRCA) y el Servicio Técnico Interamericano de Cooperación Agrícola (STICA). Para más detalles: ANCR, 3991. 
más altas de Grecia, no convencieron a los técnicos del MAG" (Vizcaíno, 1994) dieron cuenta de la problemática. El Editorial del Diario de Costa Rica del año 1963 resume la situación descrita:

"Ya hemos visto en las faldas del Irazú a los campesinos arreando sus hatos trabajosamente, desesperados porque no tienen donde llevarlos y porque no cuentan con los vehículos indispensables para hacer oportunamente los traslados en tanto que los vehículos del Ministerio de Agricultura y Ganadería han estado, o guardados en los garajes o sirviendo para que los oficiales de ese organismo aprovechen el asueto en excursiones de placer. La economía cartaginesa está destrozada. Los campesinos necesitan resolver con acelerada urgencia problemas que no tienen solución posible con los propios medios de que disponen. Frente a la indiferencia oficial, la opinión pública nacional debe reaccionar y exigir una conducta acorde con los alcances de la emergencia provocada por la actividad volcánica" (Sin Autor, 1963).

Como respuesta al Editorial el MAG afirmó lo siguiente:

"No es cierto que el Ministerio de Agricultura se haya mantenido al margen de esta emergencia. Nosotros hemos enviado a la región afectada, a varios miembros de nuestro Departamento de Veterinaria con instrucciones de prestar todo tipo de servicios a los ganaderos perjudicados por las erupciones del Volcán. Técnicos de este Ministerio están por otra parte haciendo una estimación de las pérdidas sufridas hasta ahora, con el objeto de llevar un informe concreto a conocimiento del Consejo de Gobierno, para considerar qué ayuda se puede dar a los agricultores y ganaderos damnificados" (Sin Autor, 1963).

Esta conflictividad también se vio reflejada en la concesión desigual de los créditos. El poder político y la importancia económica favorecieron la aprobación de los préstamos bancarios a sectores productivos como el cafetalero. Por ejemplo, solo durante las erupciones de 1963-1965 el Estado instauró, a petición de la Cámara Nacional de Cafetaleros, dos programas diferentes para financiar el cultivo; ellos fueron: "Mantenimiento de cafetales seriamente dañados por la ceniza volcánica" y "Repoblamiento y mejoramiento de cafetales". De hecho, ambos proyectos entraron en funcionamiento en el período de mayor intensidad volcánica del Irazú, 
Wainer Ignacio Coto-Cedeño. Nubes de ceniza, campos de arena. Actividad volcánica en Costa Rica y su impacto en el sector agropecuario, 1950-2017

mientras que el programa "Préstamos para contrarrestar los daños causados por la actividad volcánica a la agricultura y ganadería" se puso en marcha una vez que finalizó el ciclo eruptivo. Hasta el año de 1966, el número de productores beneficiados fue superior al resto de programas crediticios, incluso al que desarrolló el ITCO, véase el Cuadro No. 1.

Cuadro No. 1. Número de productores que accedieron a los programas de créditos bancarios durante las erupciones del volcán Irazú, 1963-1965

\begin{tabular}{|l|c|c|}
\hline \multicolumn{1}{|c|}{ Programa } & No. de Productores & Porcentaje \\
\hline Damnificados volcán Irazú (ITCO) & 137 & 24 \\
\hline $\begin{array}{l}\text { Mantenimiento de cafetales seriamente } \\
\text { dañados por la ceniza volcánica }\end{array}$ & 68 & 12 \\
\hline Repoblamiento y mejoramiento de cafetales & 256 & 47 \\
\hline $\begin{array}{l}\text { Préstamos para contrarrestar los daños } \\
\text { causados por la actividad volcánica a la } \\
\text { agricultura y ganadería }\end{array}$ & 90 & 17 \\
\hline Totales & $\mathbf{5 5 1}$ & $\mathbf{1 0 0}$ \\
\hline
\end{tabular}

Fuente: elaboración propia con base en ANCR, 4495.

Nota: totales hasta enero de 1966.

Los préstamos contemplaron el pago de planillas, compra de agroquímicos, abonos y otros materiales requeridos para la rehabilitación de las fincas de café afectadas por la ceniza y las plagas. No obstante, el apoyo económico estatal se extendió hasta los beneficiadores del grano. Como requisito para acceder al crédito los "industrializadores" presentaron ante la Oficina del Café una declaración jurada en la que indicaron la zona de procedencia y la cantidad de café entregado por los productores durante las épocas de cosecha de 1962-1963, 1963-1964 y 1964-1965 con el propósito de calcular la disminución en la producción (ACMAG, 1965). Los beneficiadores que recibieron el financiamiento se ubicaron en Tres Ríos, Curridabat, Montes de Oca, Coronado, Tibás, Desamparados y Heredia; el monto del crédito cubrió entre un 50 y 70 por ciento de las pérdidas reportadas (ANCR, 4495). El SBN justificó "que tales medidas contribuirán a preservar el nivel de producción interna y la exportación de café, asegurando así la subsistencia de los trabajadores rurales" (ANCR, 4542). 
En vista de las dificultades para acceder a los recursos del Estado, los productores optaron por elaborar sus propios planes de emergencia (Fotografía No. 2). La primera decisión de los ganaderos fue fortalecer e incrementar la cantidad de los controles veterinarios. Esta acción se complementó con prácticas como la limpieza de ojos, nariz y lomo de los animales. De igual manera, los finqueros dispusieron alimentar el ganado a partir de concentrados, pastos de corte y suplementos alimenticios (probióticos y aditamentos). Es fundamental señalar que los alimentos fueron suministrados bajo estrictas normas de seguridad. Por ejemplo, se techaron los abrevaderos para evitar la formación de sedimentos de arena, se lavaron los potreros antes de enviar las vacas a pastar y se sellaron las entradas de aire de los establos y galerones. Los agricultores, por su lado, eliminaron el exceso de ceniza en cultivos como el de papa, repollo, zanahoria y hortalizas a través de bombas de motor de agua y máquinas sopladoras (ANCR, 4495; Solano, 2016).

Fotografía No. 2. Trabajos de limpieza llevados a cabo por productores agropecuarios ante la caída de ceniza, erupciones del volcán Turrialba, 2016

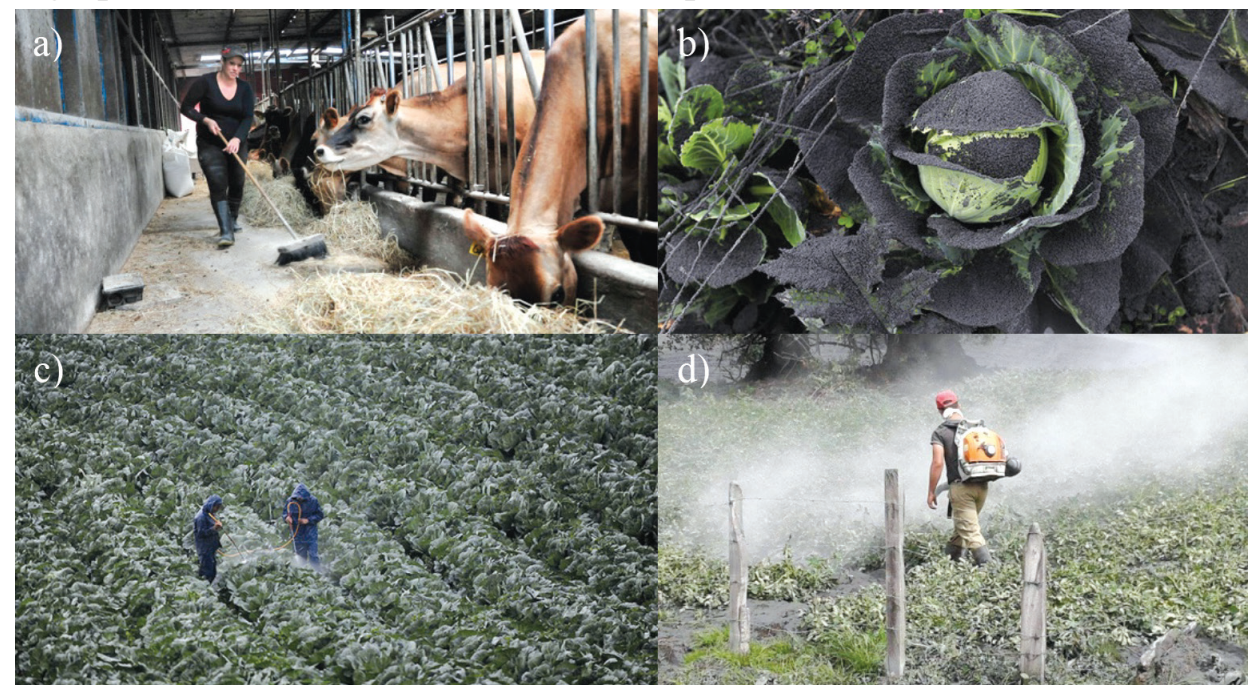

Fuente: Colección de la Comisión Nacional de Emergencias (CNE) y del Observatorio Vulcanológico y Sismológico de Costa Rica (OVSICORI).

Notas: a) eliminación de ceniza volcánica de los establos en una finca ganadera en San Gerardo de Oreamuno, Zona Norte de Cartago, b), c) y d) proceso de lavado y "soplado" de ceniza en cultivos de repollo y papa en Santa Cruz de Turrialba. 
Wainer Ignacio Coto-Cedeño. Nubes de ceniza, campos de arena. Actividad volcánica en Costa Rica y su impacto en el sector agropecuario, 1950-2017

En contraste con estas medidas, un grupo de productores prefirió migrar a regiones del país que experimentaron poca o nula afectación por la expulsión de materiales volcánicos. En algunos de los casos el traslado se dio de manera temporal, mientras que en otros fue permanente. Solo por mencionar un evento, la fuerza de las erupciones del volcán Irazú (19631965) obligó a ganaderos y productores de papa y hortalizas a emigrar a zonas como Turrialba en la provincia de Cartago, Santa María de Dota en la provincia de San José, San Ramón en la provincia de Alajuela y San Rafael en la provincia de Heredia, tal y como se observa en el Mapa No. 4. Esto con el objetivo de continuar desarrollando sus actividades productivas en dichas zonas. Estos desplazamientos, si se quiere forzados, representaron para los productores agropecuarios la única forma de garantizar el bienestar económico y la seguridad de sus familias:

"nos vinimos para La Fortuna porque en esos años reventó el Arenal, mi papá en busca de un lugar más seguro nos trajo para acá. Además estas tierras eran del ITCO y se prestaban para la agricultura y la ganadería" (Berrocal, 2015).

La época de migraciones como consecuencia de las erupciones del volcán Irazú formó parte de la historia de vida del productor Carlos Víquez Granados. Este agricultor, oriundo de Tierra Blanca de Cartago, subrayó que la formación de capas de ceniza imposibilitó una recuperación inmediata de los suelos y, por lo tanto, forzó el desplazamiento de él y otros productores a tierras aptas para el uso agropecuario. Al respecto, véase su testimonio:

"La ceniza aterró todas las parcelas que estaban sembradas de papa. Las matas de papa parecían pinitos, porque la ceniza se fue acumulando en forma de montañitas. Como estrategia que tomamos los productores fue agarrar la poca semilla de papa que había quedado e ir a cosechar a la Cima del Copey, en Santa María de Dota. Los ganaderos, los que tenían más de cincuenta cabezas de ganado, buscaron dónde trasladarse y comprar fincas en otros lugares del país que no se vieron afectados por las erupciones. Recuerdo el caso de Rafael Sanabria de Llano Grande, él era uno de los ganaderos más grandes de esta zona, alquiló una finca en Santa Cruz de Turrialba y se llevó las vacas para allá mientras pasaba la erupción. Otros trasladaron sus ganaderías al norte de Heredia" (Víquez, 2015). 
En términos generales, la adopción de estas estrategias alteró la cotidianidad de los trabajadores y la dinámica productiva de las fincas. Podría afirmarse, entonces, que las erupciones impusieron un "nuevo orden de trabajo" a los agricultores y ganaderos; el cual demandó un incremento en los costos de producción (insumos, equipo de protección, maquinaria y controles veterinarios), jornadas laborales más extensas e intensas y modificó los tiempos de siembra y cosecha de los cultivos. Una interpretación de estas alternaciones la expuso José Ángel Coto, ganadero de Santa Cruz de Turrialba, al diario La Nación: "el Turrialba me cambió la vida, me hizo echado. Yo he andado de finca en finca. El Volcán me hizo salir de La Picada, donde tengo mi propiedad" (Hernández, 2015). A pesar de las perturbaciones, los expertos subrayan el abonamiento de los suelos como el principal beneficio (en el largo plazo) de las erupciones volcánicas (Méndez y Bertsch, 2011). No obstante, sobre este último punto surge la siguiente interrogante: ¿cuál es la percepción de los productores sobre este beneficio ${ }^{13}$

13 Sobre el abonamiento de los suelos, el ingeniero agrónomo Alberto Vargas Barquero manifestó lo siguiente: "la erupción de 1963 fue un trastorno muy alto para la Zona Norte de Cartago. Posteriormente a las erupciones vino otro período muy interesante y es que con los años se dio un mejoramiento del suelo, porque se incorporaron nuevos elementos y el aspecto físico de la arena no siguió causando daños”. Véase: Vargas, 2011. 
Wainer Ignacio Coto-Cedeño. Nubes de ceniza, campos de arena. Actividad volcánica en Costa Rica y su impacto en el sector agropecuario, 1950-2017

\section{Mapa No. $4^{14}$}

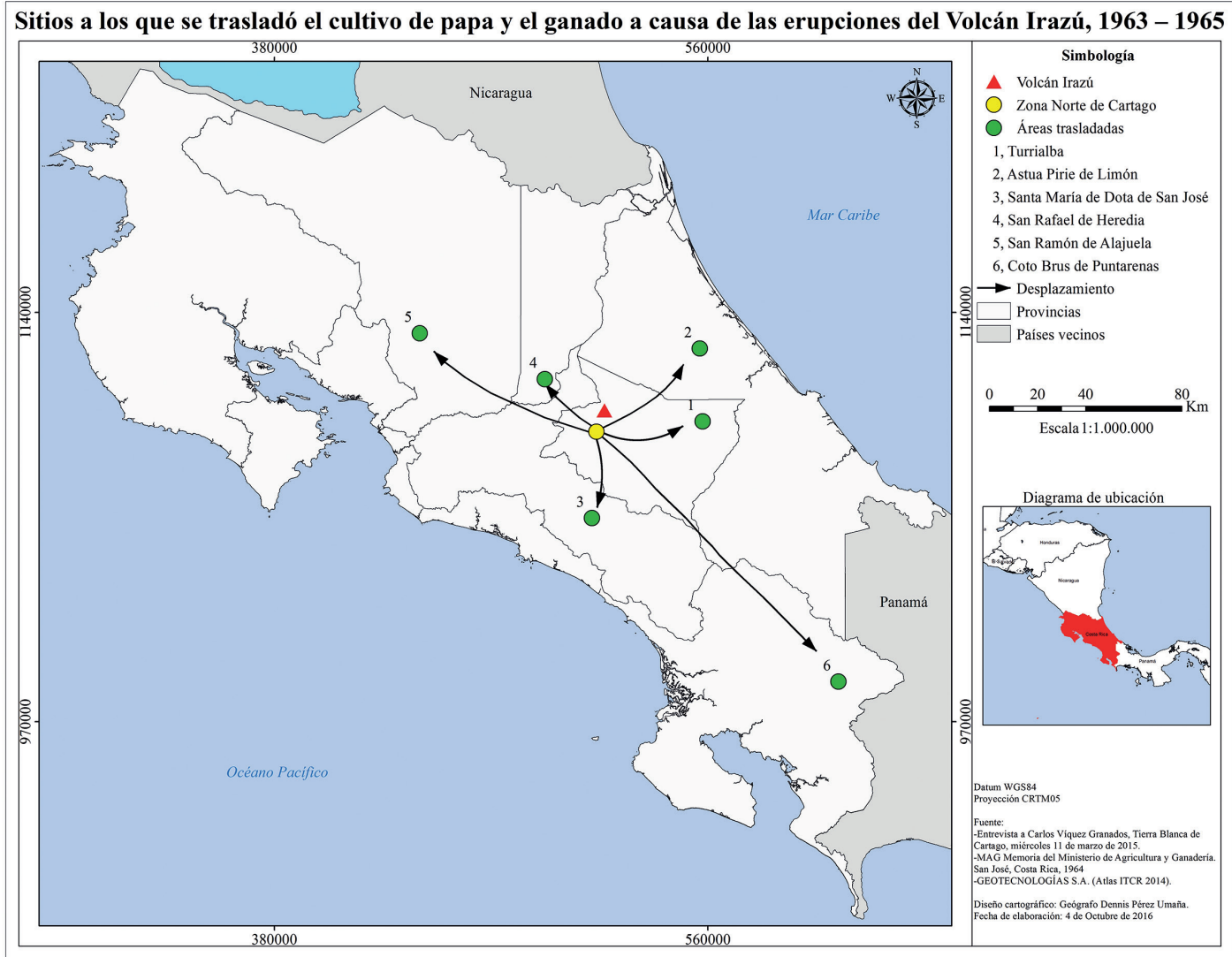

Fuente: (Granados, 2015; MAG, 1964).

\section{Conclusiones}

El estudio de las erupciones volcánicas en Costa Rica ha sido ampliamente desarrollado por científicos afines a la geología, geografía y agronomía. En oposición a este dominio de las ciencias experimentales, disciplinas como la historia se olvidaron de incluir a los volcanes dentro de sus perspectivas de análisis. La consideración de enfoques provenientes de las ciencias sociales permite ampliar el entendimiento sobre la intensa actividad volcánica que experimenta actualmente el país, y que tiene fuertes implicaciones sociales, productivas, económicas y ambientales. Es

14 El Mapa No. 4 también incluye Astúa Piere y Coto Brus, asentamientos del ITCO. 
decir, este tipo de abordajes ayuda a comprender el comportamiento de las poblaciones y las dinámicas socioproductivas ante la actividad volcánica, así como el impacto ambiental generado por las erupciones. Desde el punto de vista teórico, propuestas como la de este artículo buscan, a través de la fusión de la Historia Agro-ambiental y los postulados de la resiliencia ecológica, estudiar el fenómeno de las erupciones volcánicas desde una perspectiva socioecológica.

Para el caso costarricense, la producción agropecuaria y las erupciones volcánicas están vinculadas entre sí. De hecho, históricamente ha sido el sector agropecuario el que ha soportado el impacto directo de las erupciones. Así quedó demostrado durante los períodos de mayor actividad de los volcanes Irazú (1963-1965), Arenal (1968), Poás (1953, 1994, 2005) y Turrialba (2007-2017). En este sentido, productores del Valle Central y la provincia de Guanacaste han tenido que lidiar con la acumulación de ceniza en los campos de cultivo y pastoreo. Además, les ha tocado que enfrentar un aumento significativo en el número de plagas de insectos, las cuales han atacado plantaciones enteras de café, algodón, caña de azúcar y pastos. Como estrategia para contrarrestar los efectos de las erupciones los ganaderos reforzaron las medidas de higiene y seguridad de los hatos y en situaciones de emergencia decidieron trasladar los animales de finca. Los agricultores se enfocaron en eliminar la ceniza de los cultivos.

Contradictoria fue la reacción y el apoyo del Estado ante las problemáticas derivadas por las erupciones. Si bien es cierto que organizaciones como el Instituto de Tierras y Colonización (ITCO), el Ministerio de Agricultura y Ganadería (MAG) y el Consejo Nacional de Producción (CNP) ejecutaron programas en favor de los agricultores afectados, la distribución de los fondos económicos (e insumos agrícolas) se llevó a cabo de una manera desigual. Por ejemplo, solo para las erupciones del volcán Irazú, entre 1963-1965, el gobierno de turno autorizó la puesta en marcha de dos proyectos exclusivos para caficultores y beneficiadores del grano; los cuales otorgaron una serie de subsidios a los productores como el otorgamiento de créditos bancarios, la condenación de deudas y el pago de planillas. En otras palabras, la política crediticia para el sector agropecuario durante las erupciones volcánicas tuvo como objetivo primordial el financiamiento de cultivos exportables como el café. 
Wainer Ignacio Coto-Cedeño. Nubes de ceniza, campos de arena. Actividad volcánica en Costa Rica y su impacto en el sector agropecuario, 1950-2017

\section{Referencias}

Acevedo, M. (1976). Notas cronológicas de la actividad del Poás. Heredia, Costa Rica: Universidad Nacional.

Aguilar, I. y Alvarado, G. (2014). Pérdidas humanas y económicas causadas por el vulcanismo en Costa Rica entre 1953 y 2005. En: Revista Geológica de América Central, 51, 93-128.

Ágústsdóttir, A. (2015). Ecosystem approach natural hazard mitigation of volcanic tephra in Iceland: building resilience and sustainability. En: Natural Hazards, 78 (3), 1669-1691.

Alvarado, G. (2011). Los volcanes de Costa Rica. San José, Costa Rica: EUNED.

Alvarado, G., Vega, Ana. (2013). La geomorgología de la colada de cervantes, volcán Irazú (Costa Rica): descripción de una de los campos de lava más grandes de América Central. En: Revista Geológica de América Central, 48, 99-118.

Alvarado, G., Vargas, A., Campos, N. y Chaves, I. (2014). El riesgo derivado de la amenaza volcánica en Costa Rica. San José, Costa Rica: CNE.

Barquero, J. (1977). El volcán Irazú y su actividad. Heredia, Costa Rica: Universidad Nacional.

Barquero, R. (Editor). (2005). Los principales volcanes activos de Costa Rica. San José, Costa Rica: Red Sismológica Nacional.

Bergoeing, J.P. (2011). Costa Rica: una historia volcánica. España: Bubok Editorial.

Besoaín, E., Sepúlveda, G. y Sadzawka, A. (1992a). La erupción del volcán Lonquimay y sus efectos en la agricultura. En: Agricultura Técnica, 52 (4), 354-358.

Besoaín, E., Ruíz, R. y Hepp, C. (1995b). La erupción del volcán Hudson, XI región, y sus consecuencias para la agricultura. En: Agricultura Técnica, 55 (3-4), 204-219.

Buteler, M., Stadler, T., López, G., Lassa, M., Trombotto, D., D’Adamo. P. y Fernández, V. (2011). Propiedades insecticidas de la ceniza del complejo volcánico Puyehue-Cordón Caulle y su posible impacto ambiental. En: Revista de la Sociedad Entomológica Argentina, 70 (34), 149-156. 
Cook, R., Barron, J., Papendick, R. y Williams, G. (1981). Impact on agriculture of the Mount St. Helens eruptions. En: Science, New Series, 211, (4477), 16-22.

Elizalde, L. (2014). Volcanism and arthropods: a review. En: Ecología Austral, 24, 3-16.

Feldman, L. (1993). Mountains of fire, lands that shake: earthquakes and volcanic eruptions, in the historic past of Central America (15051899). California: Labyrinthos.

Gardner, J. y Dekens. (2007). Mountains hazards and the resilience of socio-ecological systems: lessons learned in India and Canada. En: Natural Hazards, 41 (2), 317-336.

Gerrard, C. y Petley, D. (2013). A risk Society? Environmental hazards, risk and resilience in the later Middle Ages in Europe. En: Natural Hazards, 69 (1), 1051-1079.

González de Molina, M. (2003). La Historia Ambiental y el fin de la "utopía metafísica" de la modernidad. En: Aula-Historia Social, 12, 18-42.

González de Molina, M. (2011). Agroecología e Historia Agraria. Una hibridación necesaria. En: Estudio Rurales, 1 (1), 13.

Hilje, L. y Saunders, J. (2008). Manejo integrado de plagas en Mesoamérica: aportes conceptuales. Cartago, Costa Rica: Editorial Tecnológica de Costa Rica.

Holling, C. S. (1973a). Resilience and stability of ecological systems. En: Annual Review of Ecology and Systematics, (4), 18-21.

Holling, C. S. (2001b). Understanding the complexity of Economic, ecological, and social systems. En: Ecosystems, 4, 390-405.

Horton, R. y McCaldin, R. (1964). Observations on air pollution aspects of Irazú Volcano, Costa Rica. En: Public Health Reports, 79 (10), 927.

ITCO. (1964). Programa de colonización para damnificados por la actividad volcánica del Irazú. San José, Costa Rica: ITCO.

MAG. (1963). Memoria del Ministerio de Agricultura y Ganadería. San José, Costa Rica: MAG.

MAG. (1964). Memoria del Ministerio de Agricultura y Ganadería. San José, Costa Rica: MAG.

MAG. (1968). Memoria del Ministerio de Agricultura y Ganadería. San José, Costa Rica: MAG. 
Wainer Ignacio Coto-Cedeño. Nubes de ceniza, campos de arena. Actividad volcánica en Costa Rica y su impacto en el sector agropecuario, 1950-2017

MAG. (1969). Memoria del Ministerio de Agricultura y Ganadería. San José, Costa Rica: MAG.

MAG. (2016). Informe de Rendición de Cuentas. San José, Costa Rica: MAG. Martínez, A., et. Al. (2013). Ashes in the air: the effects of volcanic ash emissions on plant-pollinator relationships and possible consequences for apiculture. En: Apidologie, 44, 268-277.

Masciocchi, M., Pereira, A. y Lantschner, M. (2013). Of volcanoes and insects: the impact of the Puyehue-Cordon Caulle ash fall on populations of invasive social wasps, Vespula spp. En: Ecological Research, 28, 199-205.

Méndez, J.C. y Bertsch, F. (2011). Contenido total y disponibilidad de nutrimento en dos muestras de cenizas expulsadas en enero del 2010 por el volcán Turrialba, Costa Rica. En: Agronomía Costarricense, 35 (2), 97-104.

Meritano, J. (2011). Manejo integral de cuencas hidrológicas y la prevención de los desastres naturales. México, Puebla: Benemérita Universidad Autónoma de Puebla.

Mora, R., et. Al. (2004). La actividad de los volcanes de la Cordillera Central, Costa Rica, entre 1998-2002. En: Revista Geológica de América Central, 30, 189-197.

Müller, F., Burkhard, B. y Kroll, F. (2010). "Resilience, integrity and ecosystems dynamics: bridging ecosystems theory and management". Landform-structure, evolution, process control. Berlín: Springer, 221-242.

Paton, D., Millar, M. y Johnsoton, D. (2001). Community resilience to volcanic hazard consequences. En: Natural Hazards, 24 (2), 157-169.

Pirk, G. (2014). Did ash fall Puyehue-Cordón Caulle volcanic complex affect ant abundance and richness in the Patagonian steppe? En: Ecología Austral, 24, 23-30.

Ruíz, M. y Jiménez, E. (1968). Efecto residual de la ceniza volcánica en la calidad fotosintética del cafeto. En: Café, 9 (2), 6-11.

Scarpati, C., Perrota, A. y Ferdinando, G. (2016). Impact of explosive volcanic eruptions around Vesuvius: a story of resilience in Roman time. En: Bulletin of Volcanology, 78 (21), 1-6.

Sherrod, D., Vallance, J., Tapia, A. y McGeehin, J. (2008). Volcán Barú. Eruptive history and volcano hazards assessment. Virginia: USGS. 
Toledo, V. (2015). ¿De qué hablamos cuando hablamos de sustentabilidad? Una propuesta ecológico política. En: Interdisciplina, 3 (7), 38.

Watson, F. (2003). Environmental History. En: The Scottish Historical Review, 82 (14), 285-294.

Wille, A. y Fuente, G. (1975). Efecto de la ceniza del volcán Irazú (Costa Rica) en algunos insectos. En: Revista de Biología Tropical, 23 (2), 165-175.

\section{Documentos de Archivo}

ANCR. Fondo Bancos. 3991. Expediente sobre el otorgamiento de facilidades de amortización a los agricultores afectados por las cenizas del volcán Poás.

ANCR. Fondo Bancos. 4495. Emergencia Volcán Irazú, 1963-1965.

ANCR. Fondo Bancos. 4542. Reglamento para préstamos a damnificados con las cenizas del volcán Irazú.

ANCR. Fondo Bancos. 4732. Expediente sobre el volcán Arenal.

ANCR. Fondo José Fidel Tristán Fernández. 000001. Narración de la erupción del volcán Irazú realizada por Diego de la Haya Fernández, Gobernador de la Provincia de Costa Rica.

ANCR. Fondo Manuel Mora Valverde. 1453. Proyecto de Ley para expropiación de terrenos dañados a causa de las erupciones del volcán Arenal para declararlas Reserva Nacional.

ANCR. Fondo Ministerio de Agricultura y Ganadería. 0733. Alimentos para familias de agricultores afectadas por las erupciones del volcán Arenal.

ANCR. Fondo Ministerio de Gobernación. 002576. Programa desocupados erupciones del Irazú.

ANCR. Fondo Ministerio de Relaciones Exteriores. 8875. Problemática de plagas en el cultivo de algodón.

Archivo Central del Ministerio de Agricultura y Ganadería (ACMAG). Compilación de Leyes y Decretos del Sector Agropecuario de Costa Rica, 1949-1984: Decreto No. 44 del 28 de julio de 1965. 
Wainer Ignacio Coto-Cedeño. Nubes de ceniza, campos de arena. Actividad volcánica en Costa Rica y su impacto en el sector agropecuario, 1950-2017

\section{Artículos de periódico}

Barquero, M. (02 de junio, 2007). Erupción del Turrialba afecta ganado lechero. La Nación. San José, Costa Rica. (S.P.).

Barquero, M. (23 de febrero, 2017). 850 millones de colones perdió el sector agropecuario por ceniza del Turrialba. La Nación. San José, Costa Rica. Recuperado de: http:/www.nacion.com/economia/agro/ millones-sector-agropecuario-ceniza-Turrialba_0_1617638221.html Barquero, M. (23 de febrero, 2017). 850 millones de colones perdió el sector agropecuario por ceniza del Turrialba. La Nación. San José, Costa Rica. (S.P.).

Fuentes, J. (11 de junio, 1994). Lluvia ácida desplaza a agricultores. La República. San José, Costa Rica (p. 4A).

Hernández, J. (15 de noviembre, 2015). El volcán Turrialba me cambió la vida: me hizo echado. La Nación. San José, Costa Rica. Recuperado de: http://www.nacion.com/sucesos/desastres/volcan-cambio-vidahizo-echado_0_1524447575.html

Mata, E. (13 de mayo, 2016). Ceniza del Turrialba podría seguir cayendo en San José por años. La Nación. San José, Costa Rica. Recuperado de: http://www.nacion.com/nacional/politica/Geologo-advierte-Turrialba-San-Jose 0 1560444068.html

Sin Autor. (09 de agosto, 1968). BID aporta \$ 600000 para la emergencia del volcán Arenal. San José, Costa Rica. La Nación. San José, Costa Rica (pp. 32-33).

Sin Autor. (11 de abril, 1964). 14500 manzanas de café afectan plagas. La Prensa Libre. San José, Costa Rica. (pp. 1 y 6).

Sin Autor. (11 de agosto, 1968), La sequía es el principal factor que afecta a los cultivos de Guanacaste. La Nación. San José, Costa Rica. (p. 32).

Sin Autor. (15 de agosto, 1968). Autorizada venta de 3600 cabezas de la Cámara de Ganaderos de Abangares. La Nación. San José, Costa Rica. (p. 33).

Sin Autor. (21 de junio, 1990). Declarados zona de desastre cuatro cantones alajuelenses. La República. San José, Costa Rica. (p. 2A).

Sin Autor. (21 de marzo, 1963). El Irazú y el MAG. Diario de Costa Rica. San José, Costa Rica. (Editorial).

Sin Autor. (22 de marzo, 1963). Destruidas más de cinco mil manzanas. La Nación. San José, Costa Rica. (p. 32). 
Sin Autor. (22 de marzo, 1963). MAG sí está prestando ayuda a los agricultores. Diario de Costa Rica. San José, Costa Rica. (p. 6).

Sin Autor. (22 de marzo, 1963). Ninguna ayuda del MAG para los agricultores del Irazú. Diario de Costa Rica. San José, Costa Rica. (p. 4).

Solano, H. (17 de octubre, 2016). Hasta la comida sabe a ceniza en las fincas de San Gerardo. La Nación. San José, Costa Rica. Recuperado de: http://www.nacion.com/sucesos/desastres/fincas-San-Gerardo-comida-ceniza_0_1591840819.html

Vizcaíno, I. (12 de agosto, 1994). Aseguran que Poás no causó pérdidas. La Nación. San José, Costa Rica. (p. 16A).

\section{Entrevistas}

Murillo Berrocal, Freddy. (06 de marzo, 2015). Ganadero, Coopevega de San Carlos, Costa Rica.

Vargas Barquero, Alberto. (09 de septiembre, 2011). Ingeniero agrónomo, La Uruca, San José, Costa Rica.

Víquez Granados, Carlos. (11 de marzo, 2015). Productor de papas, Tierra Blanca de Cartago, Costa Rica. 